\title{
Engenharia das catástrofes: entre o determinístico \\ e o imponderável
}

JOÃO FRA NCISCO JUSTO FILHO

e José Roberto CASTILHO PIQUEIRA

$C 6$ E ALGo pode dar errado, dará errado da pior maneira, no pior momento e de modo a causar o maior estrago possível." Essa é uma das variantes da famosa Lei de Murphy, enunciada nos anos 1960 pelo engenheiro da Nasa Edward Murphy. Ela agrega um significado matemático aos eventos catastróficos, ao associar um caráter determinístico à maioria desses eventos. Assim, se existe uma probabilidade finita de algum evento catastrófico acontecer, em algum momento, ele certamente vai acontecer. A incerteza estaria presente somente no elemento temporal, ou seja, quanto tempo levaria para ocorrer. Eventos com essa classificação contrastam totalmente de outros que realmente poderiam ser chamados de acidentes, aqueles em que estão primordialmente associados a elementos aleatórios, randômicos, imponderáveis e, portanto, imprevisíveis.

Inundações, deslizamentos, furacões, erupções vulcânicas, terremotos, tsunamis e nevascas são eventos que transcendem, em escala temporal, a existência humana. Muitos deles, como inundações e furações, são inclusive eventos cíclicos, e acontecem em determinadas regiões do planeta com periodicidade anual. Portanto, eles não deveriam ser classificados como imprevisíveis, mas como eventos naturais de um planeta em constante mutação. Muitos deles são previsíveis com grande precisão; por exemplo, nas grandes cidades, toda vez que chove, inundações são observadas nos mesmos locais, não importando muito a quantidade de chuva. Não poderia existir uma relação causal mais exata do que essa.

A ocupação humana causa importantes transformações na natureza, podendo até amplificar o impacto desses eventos naturais, em termos de perdas materiais e de vidas. Desde a pré-história, o homem ocupa regiões com riscos de catástrofes, mas isso não foi casual. Áreas próximas a vulcões são geralmente muito férteis para a agricultura, a presença humana nas cercanias de oceanos e rios favorece o transporte e a irrigação de plantações. Mas como tirar proveito dessas vantagens da natureza em regiões onde os riscos de catástrofes são tão grandes? O homem é vítima dos eventos naturais na proporção que, em muitas vezes, imagina que pode interferir na natureza e dominá-la, ao invés de tentar 
integrar-se a ela e aprender com os seus eventos inerentes, com sua dinâmica natural, entender esses mecanismos naturais, para então tomar proveito deles.

A chave de tudo, então, passa por entender esses fenômenos naturais. A história humana sempre foi permeada pelos desenvolvimentos científicos, não somente pela curiosidade em conhecer a fenomenologia da natureza, mas também pelo caráter da utilidade desse conhecimento. Quanto mais discernimento a humanidade tem da natureza, mais consegue se distanciar de interpretar as catástrofes através de elementos dogmáticos ou imponderáveis. Portanto, a imprevisibilidade desses eventos naturais tende a diminuir na medida em que a humanidade melhora seu conhecimento da natureza, e consegue construir modelos para fazer previsões desses eventos para evitar, ou pelo menos minimizar, as consequências catastróficas.

Dessa maneira, não se pode afirmar que o clima é imprevisível ou que a quantidade de chuvas é imponderável, para justificar alguma inundação que tenha causado grandes perdas. Fosse assim, a meteorologia não seria ciência. $\mathrm{O}$ que se pode dizer, aí sim, é que os eventos climáticos envolvem muitas variáveis de correlações altamente não lineares. Portanto, os modelos teóricos do clima são ainda muito simplificados para conseguir capturar toda essa fenomenologia, o que acaba por levar a uma menor precisão na previsibilidade dos eventos climáticos. Mas não é a ciência do clima que está errada ou que é incapaz de fazer previsões do clima, uma melhoria da percepção dos eventos climáticos será alcançada quando modelos mais sofisticados forem desenvolvidos.

O caso dos furacões é um exemplo bastante interessante. Os recentes avanços tecnológicos de monitoramento por satélite possibilitam prever, com grande precisão a evolução de qualquer furacão. Isso permite que as autoridades governamentais tomem providências para evacuar as populações das regiões que estiverem em sua trajetória. Por exemplo, o furacão Andrews, que atingiu os Estados Unidos em 1992 e foi classificado em segundo lugar em termos de perdas materiais naquele país, causou menos de 100 mortes, uma vez que procedimentos de evacuação foram executados a tempo. Quando esses dados são comparados com aqueles de tempestades tropicais recentes no Brasil, fica claro quão distante o poder público do país está em administrar esse tipo de evento.

Equivalentemente, poder-se-ia discutir a possibilidade de previsão de terremotos, e consequentemente tsunamis, pelos estudos em geofísica. Hoje, se consegue medir com grande precisão a tensão armazenada entre duas placas tectônicas, o que permite prever que um evento sísmico pode ser iminente naquela região. Mas as escalas temporais dos eventos geológicos são de milhares a milhões de anos, e iminente nessa área pode simplesmente significar um intervalo de tempo de anos ou décadas. Esses exemplos mostram a relevância de se ter um profundo conhecimento da natureza, para a humanidade poder tirar proveito dela e ainda prevenir, ou pelo menos minimizar, os efeitos de eventos naturais catastróficos. A maioria desses eventos é altamente determinístico e, portanto, 
a sociedade brasileira não pode mais aceitar palavras como "imponderável" para descrevê-los.

O Brasil observa uma janela de oportunidade para promover o seu desenvolvimento econômico. Nesse ambiente de ufanismo, discute-se o aumento do PIB e a melhora no poder de compra da população, certamente avanços importantes. O debate sobre os desafios para um crescimento sustentável geralmente circunda temas de infraestrutura, de energia, de estradas e portos. Entretanto, não vem à tona que crescimento sustentável também deveria significar propiciar uma vida melhor para a sociedade e, portanto, proteger as populações de eventos catastróficos. Os recentes eventos de chuvas e inundações em diversas partes do país, assim como tantas outras catástrofes observadas nos últimos anos, evidenciaram que o país ainda está muito distante de responder satisfatoriamente a esses eventos, quando comparado com outros países que enfrentam situações similares.

Considerando a previsibilidade de grande parte desses eventos catastróficos, a omissão da sociedade civil, com os riscos inerentes desses eventos, é preocupante. Em meio ao otimismo pelas perspectivas de crescimento econômico, observa-se a baixa percepção que a população tem da dificuldade, da quantidade de conhecimento necessária, do tempo de estudo e, especialmente, do nível de investimento para projetos condizentes com a complexidade que as relações humanas passaram a ter no mundo das novas tecnologias. Evidencia-se, assim, a baixa apreciação da população pelas engenharias e áreas afins, aquelas que deveriam ser as protagonistas em encontrar soluções para minimizar os efeitos causados por esses eventos.

Um país somente consegue fazer a gestão desses eventos se investir em diversas frentes, primeiro tendo um corpo de cientistas e engenheiros que estudem os fenômenos naturais e construam um sistema unificado de prevenção de catástrofes. $\mathrm{O}$ conhecimento dos riscos de catástrofes em regiões localizadas podem levar os governos a tomar ações preventivas, como remoção de populações de áreas de risco, obras de engenharia que permitam adequação de certas regiões, minimizando os riscos ou diminuindo os impactos dos eventos. Isso requer grandes investimentos em educação, desde o ensino básico até o universitário, incluindo investimento em pesquisa nas instituições de nível superior. Adicionalmente, requer investimentos em obras de engenharia que atendam a essas demandas.

É necessário ainda criar uma agência integrada de gestão de crises, que inclua governos municipais, corpo de bombeiros, forças policiais e defesa civil. Uma vez identificadas as situações de risco ou de emergência, essa agência poderia organizar a evacuação das populações afetadas, ou ainda, responder rapidamente às consequências dos eventos catastróficos.

Mesmo que as chuvas já tenham passado, já se pode prever, com grande precisão, que eventos como esses acontecerão no próximo verão. Portanto, é 
necessária uma resposta imediata da sociedade para que os efeitos futuros possam ser minimizados. Em meio a esses eventos catastróficos, os administradores públicos evocaram elementos imponderáveis para descrevê-los, ou pelo menos justificá-los, de tal forma a tentar se isentar de qualquer responsabilidade. Agora decidiram montar um sistema de previsão de catástrofes. Pelo menos poderão eles tentar se proteger da catástrofe de acabarem perdendo seus próprios empregos.

RESUMO - Os eventos catastróficos são geralmente classificados pela sociedade como acidentes da natureza. Entretanto, uma abordagem mais científica mostra claramente que a maioria desses eventos é altamente determinística e, portanto, pode ser prevista. Cabe aos cientistas desmistificar a interpretação dogmática desses eventos, e usar o conhecimento adquirido pela ciência para fazer previsões precisas de suas ocorrências. Dessa forma, a sociedade poderá cobrar da gestão pública medidas mais efetivas na prevenção dos efeitos de catástrofes naturais.

PALAVRAS-CHAVE: Desastres naturais, Determinismo, Catástrofes, Gestão pública, Lei de Murphy.

ABSTRACT - The catastrophic events are generally classified as natural accidents. However, a more scientific approach shows unambiguously that most of those events are highly deterministic, such that they could be predicted. Scientists should demystify a dogmatic interpretation of those events, and use their knowledge to provide precise predictions of their occurrence. Therefore, society will be able to demand from public government more effective actions to prevent the adverse effects of those natural catastrophes.

KErWORDs: Natural disasters, Determinism, Catastrophes, Public administration, Murphy's law.

João Francisco Justo Filho é doutor em Engenharia Nuclear pelo Massachusetts Institute of Technology (MIT) e professor da Escola Politécnica da Universidade de São Paulo. @- jjusto@lme.usp.br

José Roberto Castilho Piqueira é doutor em Engenharia Elétrica pela Universidade de São Paulo, vice-diretor da Escola Politécnica da Universidade de São Paulo e diretorpresidente da Sociedade Brasileira de Automática. @ - piqueira@lac.usp.br

Recebido em 16.4.2011 e aceito em 21.6.2012. 